\title{
Ab initio calculations of charged point defects in GaN
}

\author{
A. Gulans ${ }^{{ }^{1}}$, R. A. Evarestov ${ }^{2}$, I. Tale ${ }^{1}$, and C. C. Yang ${ }^{3}$ \\ ${ }^{1}$ Institute of Solid State Physics, University of Latvia, 8 Kengaraga, Riga LV-1063, Latvia \\ ${ }^{2}$ St. Petersburg State University, Chemistry Department, University prospekt 26, St. Petersburg 198504, \\ Russia \\ ${ }^{3}$ Graduate Institute of Electro-Optical Engineering, National Taiwan University, 1, Roosevelt Road, \\ Sec. 4, Taipei, Taiwan
}

Received 11 July 2004, revised 20 July 2004, accepted 30 July 2004

Published online 20 January 2005

PACS 61.72.Ji, 71.15.Mb, 71.55.Eq

The Generalized Gradient Approximation (GGA) of a Density Functional Theory (DFT) in LCAO basis is used to determine electronic structure of charged point defects in hexagonal GaN. Impurities of $\mathrm{Mg}_{\mathrm{Ga}}$, $\mathrm{Zn}_{\mathrm{Ga}}, \mathrm{Si}_{\mathrm{N}}$ and $\mathrm{C}_{\mathrm{N}}$ (the most common dopants) were considered for charge states $0, \pm 1,-2$. The vacancies of $\mathrm{V}_{\mathrm{Ga}}$ and $\mathrm{V}_{\mathrm{N}}$ were considered for charge states 0 and $0, \pm 1, \pm 2$ respectively. The defects in consideration are compared from the point of view of the one-electron states localization. All the calculations were performed for a supercell containing 96 atoms. The divergence due to periodically repeated charges has been eliminated by the use of a uniform background charge of an opposite sign.

(c) 2005 WILEY-VCH Verlag GmbH \& Co. KGaA, Weinheim

1 Introduction Gallium nitride $(\mathrm{GaN})$ is a wide-gap semiconductor being a promising compound in the field of electronic and optoelectronic devices. Its properties depend on the point defects which are present in the material. Despite a number of published calculations the electronic structure of the point defects of $\mathrm{GaN}$ is far from being understood. One of unsolved problems is a calculation of single defects in different charge states. The most accurate method would be based on use of Green's-functions and an embedded cluster model. However, it would be computationally too demanding compared to a periodic model (the supercell approximation). Since Coulomb interaction is long-range the supercell total energy diverges. One way to solve this problem is to include in calculations an uniform background charge of opposite sign. Unfortunately the obtained in this approach the total energy still includes the interaction of periodically repeated defects. It is possible to exclude its contribution from the total energy applying a posteriori corrections $[1,2]$.

$\mathrm{Ab}$ initio calculations of different charge states of single defects (vacancies $\mathrm{V}_{\mathrm{Ga}}$ and $\mathrm{V}_{\mathrm{N}}$ and impurities $\mathrm{Mg}_{\mathrm{Ga}}, \mathrm{Zn}_{\mathrm{Ga}}, \mathrm{C}_{\mathrm{N}}$ and $\mathrm{Si}_{\mathrm{N}}$ ) in hexagonal GaN have been performed in this work. The point defects in consideration are well known dopants in $\mathrm{GaN}$ and the corresponding local levels are formed in the band gap. It was taken into account the atomic relaxation of nearest and next nearest neighbours of the point defect.

2 Computational details The ab initio calculations have been performed using LCAO code CRYSTAL2003 [3] within PWGGA [4] (Perdew-Wang Generalized Gradient Approximation) of spinpolarized DFT (Density Functional Theory) Hamiltonian.

In the point defect calculations it is important that both extended states and localized states of a single defect are represented well [5]. The first ones can be obtained with a sufficient quality even with $\mathbf{k}=0$ approximation in the Brillouin zone summing if the size and shape of the supercell are appropriate. A

"Corresponding author: e-mail: sf90046@lanet.Iv 
good description of localized states requires that the interaction of periodically repeated defects is weak. A criterion for that can be a convergence of the charge density near the boundary of the defective crystal supercell chosen to the charge density distribution of the host crystal.

In order to ensure an acceptable quality of the representation of extended states, one has to do calculations for a supercell increasing its size until convergence of the total energy is reached. Alternative approach which is used in current paper is based on one-to-one correspondence of $\Gamma$-point supercell calculations and primitive unit cell calculations with a summation over special points of Brillouin zone.

Any supercell can be described by an extension matrix $l$, which is defined from a relation

$$
\mathbf{A}_{j}=\sum_{i=1}^{3} l_{i j} \mathbf{a}_{i}, \operatorname{det}(l)=N,
$$

where $\mathbf{a}_{i}$ are translation vectors of the primitive cell, $\mathbf{A}_{i}$ are translation vectors of the supercell and $\mathrm{N}$ is a number of primitive unit cells in a supercell. A non-diagonal $l$ is used in current work. It can be written in form

$$
l^{\prime}=\left(\begin{array}{ccc}
2 s_{1} & s_{1} & 0 \\
-s_{1} & s_{1} & 0 \\
0 & 0 & s_{2}
\end{array}\right), N=3 s_{1}^{2} s_{2},
$$

where $s_{1}$ and $s_{2}$ are positive integers. Value $s_{1}=s_{2}=2$ was enough to eliminate the short-range interaction of periodically repeated neutral defects in $\mathrm{GaN}[6]$ and was used for the charged point defects also. In these calculations the relaxation of two nearest to the point defect neighbours was considered basing on the preliminary investigation of defects states localization.

Calculations of the supercells containing the point defects have been done with $2 \times 2 \times 2$ MonckhorstPack k-mesh [7] for both vacancies and impurities.

3 Results and discussion Table 1 shows the bond length change in defective crystal relatively to the bond length in the perfect crystal. The positive values correspond to the outward relaxation.

\begin{tabular}{|c|c|c|c|c|c|c|c|}
\hline \multirow[t]{2}{*}{ Defect } & \multicolumn{2}{|c|}{$\begin{array}{c}\text { Bond length } \\
\text { change, } \%\end{array}$} & \multirow[t]{2}{*}{$M$} & \multirow[t]{2}{*}{ Defect } & \multicolumn{2}{|c|}{$\begin{array}{c}\text { Bond length } \\
\text { change, } \%\end{array}$} & \multirow[t]{2}{*}{$M$} \\
\hline & $1 \mathrm{NN}$ & $2 \mathrm{NN}$ & & & $1 \mathrm{NN}$ & $2 \mathrm{NN}$ & \\
\hline $\mathrm{V}_{\mathrm{N}}^{2+}$ & 7.3 & 8.6 & 3 & $\mathrm{Zn}_{\mathrm{Ga}}{ }^{+}$ & 2.9 & 3.1 & 3 \\
\hline $\mathrm{V}_{\mathrm{N}}^{+}$ & 7.3 & 8.5 & 3 & $\mathrm{Zn}_{\mathrm{Ga}}{ }^{\mathrm{G}}{ }^{0}$ & 3.4 & 3.7 & 3 \\
\hline $\mathrm{V}_{\mathrm{N}}^{0}$ & 3.9 & 3.7 & 6 & $\mathrm{Zn}_{\mathrm{Ga}}^{-}$ & 4.2 & 4.7 & 5 \\
\hline $\mathrm{V}_{\mathrm{N}}$ & -9.8 & -9.7 & 7 & $\mathrm{Zn}_{\mathrm{Ga}}{ }^{2-}$ & 1.2 & 2.4 & 6 \\
\hline $\mathrm{V}_{N}^{2-}$ & -14.2 & -12.1 & 8 & $\mathrm{C}_{\mathrm{N}}^{+}$ & 0.5 & 0.7 & 4 \\
\hline $\mathrm{V}_{\mathrm{Ga}}{ }^{0}$ & 4.3 & 4.6 & 6 & $\mathrm{C}_{\mathrm{N}}^{\mathrm{N}}$ & -0.3 & -0.3 & 3 \\
\hline $\mathrm{Mg}^{+}$ & 4.3 & 4.4 & 6 & $\mathrm{C}_{\mathrm{v}}$ & -2.1 & -2.4 & 3 \\
\hline $\mathrm{Mg}_{\mathrm{Ga}}{ }^{0}$ & 4.3 & 4.6 & 5 & $\mathrm{C}_{\mathrm{N}}{ }^{2-}$ & -2.1 & -2.3 & 3 \\
\hline $\mathrm{Mg}_{\mathrm{Ga}}$ & 4.4 & 4.8 & 5 & $\mathrm{Si}_{\mathrm{N}}^{+}$ & 13.0 & 15.1 & 15 \\
\hline $\mathrm{Mg}_{\mathrm{Ga}^{2}}$ & 4.3 & 4.6 & 5 & $\mathrm{Si}_{\mathrm{N}}{ }^{0}$ & 10.2 & 11.1 & 11 \\
\hline & & & & $\mathrm{Si}_{\mathrm{N}}$ & 8.8 & 8.8 & 11 \\
\hline & & & & $\mathrm{Si}_{\mathrm{N}}{ }^{2-}$ & 9.1 & 9.2 & 11 \\
\hline
\end{tabular}

Table 1 The results of the charged point defect calculations. 
Table 1 shows the existence of an inwards relaxation for some negatively charged defects at the nitrogen site $\left(\mathrm{V}_{\mathrm{N}}^{-}, \mathrm{V}_{\mathrm{N}}{ }^{2-}, \mathrm{C}_{\mathrm{N}}{ }^{-}, \mathrm{C}_{\mathrm{N}}{ }^{2-}\right)$. We explain this by the attraction of positively charged gallium ions to the negatively charged defect. On the other hand outwards relaxations have been obtained for $\mathrm{Si}_{\mathrm{N}}{ }^{-}$and $\mathrm{Si}_{\mathrm{N}}{ }^{2-}$. This can be explained by greater sizes of $\mathrm{Si}^{-}$and $\mathrm{Si}^{2-}$ ions compared to $\mathrm{C}^{-}$and $\mathrm{C}^{2-}$ ions. In table 1 there are also given the numbers $M$ of atomic spheres starting from which the atomic point charges in defective and perfect crystals: a) practically coincide for $\mathrm{V}_{\mathrm{Ga}}, \mathrm{Mg}_{\mathrm{Ga}}$ and $\mathrm{Zn}_{\mathrm{Ga}}$, b) differ by 0.16 e for $\mathrm{V}_{\mathrm{N}}, \mathrm{C}_{\mathrm{N}}$ and $\mathrm{Si}_{\mathrm{N}}$.

As an example Fig. 1 shows the density of states for the point defects $\mathrm{Mg}_{\mathrm{Ga}}{ }^{0}, \mathrm{Mg}_{\mathrm{Ga}}{ }^{-}$(type I) and $\mathrm{Si}_{\mathrm{N}}{ }^{0}$, $\mathrm{Si}_{\mathrm{N}}{ }_{\mathrm{N}}$ (type II). For the defect of type I there are no local states in the band gap independently on the charge state. For the defect of the type II the local levels depend on the charge state: a) in the case of odd number of electrons ( $\mathrm{Si}$ atom at $\mathrm{N}$ site) it takes place the splitting of alpha- and beta-spin states, $\mathrm{b}$ ) in the case of even number of electrons ( $\mathrm{Si}^{-}$ion at $\mathrm{N}$ site) this splitting is absent. In our calculation it was found that the point defect $\mathrm{Mg}_{\mathrm{Ga}}$ belongs to the type I, the rest ones belong to the type II. Only the nitrogen vacancy forms local levels near the conduction band bottom.

Table 1 shows that the atomic relaxation around the point defect depends on a charge state and appears to be the largest for $\mathrm{V}_{\mathrm{N}}$ and $\mathrm{Si}_{\mathrm{N}}$. The most distant charge redistribution around the point defect was found for the same point defects.

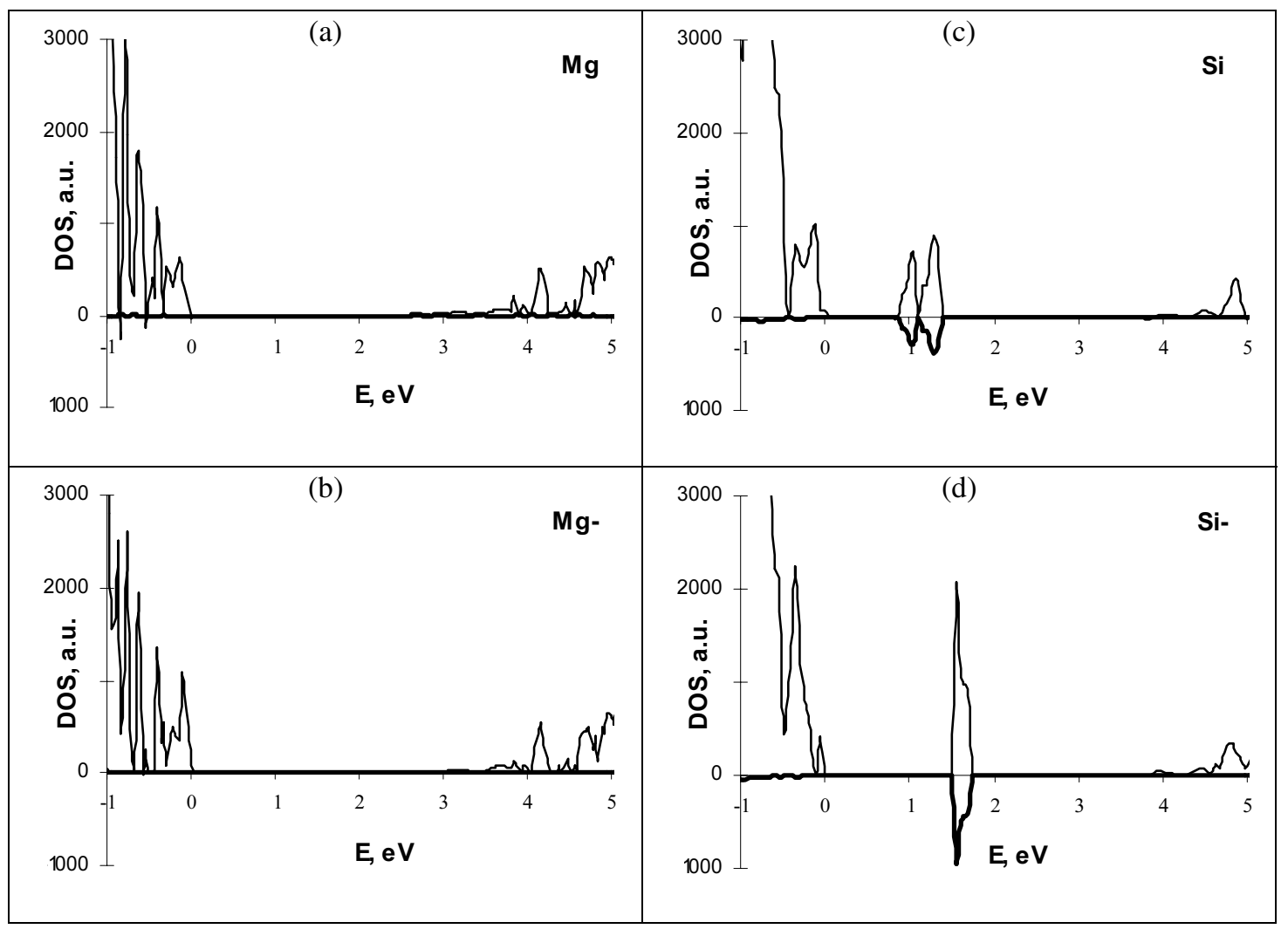

Fig. 1 Total (thin line) and projected (bold line) density of states. Data are shown for (a) $\mathrm{Mg}_{\mathrm{Ga}}$, (b) $\mathrm{Mg}_{\mathrm{Ga}}$, (c) $\mathrm{Si}_{\mathrm{N}}$ and (d) $\mathrm{Si}_{\mathrm{N}}$ impurities. Zero energy corresponds to the valence band top, the calculated energy gap is $2.7 \mathrm{eV}$.

Table 2 shows a dependence of the change of the total energy on the charge state for the supercell chosen. It is seen that for all point defects in consideration the variation of charge from +1 to 0 and from 0 to -1 gives small changes of the total energy difference $(0.1-0.5 \mathrm{eV})$. At the same time the variation of charge from -1 to -2 practically does change the total energy for $\mathrm{V}_{\mathrm{N}}$ and is relatively large $(3.3-4.4 \mathrm{eV})$ 
for all other defects. We give the following explanation for this. Only nitrogen atom vacancy gives local levels near the bottom of the conduction band, so that adding of one electron gives small changes of the total energy of the supercell.

For the point defects in consideration it could be possible to calculate the formation energy. However, such a calculation requires the corrections introduced in $[1,2]$ for supercell model of charged point defects. Taking into account this correction would decrease the total energy differences for different charge states. Our preliminary estimation, however, shows that this decreasing is about $0.5-1.0 \mathrm{eV}$.

Table 2 The supercell total energy differences for different charge states of the point defect in $\mathrm{GaN} .+/ 0$, $0 /$ - and - $/ 2$ - mean change of charges from +1 to 0,0 to -1 and -1 to -2 respectively.

\begin{tabular}{|l|c|c|c|}
\hline \multirow{2}{*}{ Defect } & \multicolumn{3}{|c|}{ Total energy difference, $\mathrm{eV}$} \\
\cline { 2 - 4 } & $+/ 0$ & $0 /-$ & $-/ 2-$ \\
\hline $\mathrm{V}_{\mathrm{N}}$ & 14.3 & 14.5 & 14.5 \\
\hline $\mathrm{Mg}_{\text {Ga }}$ & 11.0 & 11.1 & 15.2 \\
\hline $\mathrm{Zn}_{\mathrm{Ga}}$ & 11.1 & 11.3 & 15.3 \\
\hline $\mathrm{C}_{\mathrm{N}}$ & 11.4 & 11.7 & 16.1 \\
\hline $\mathrm{Si}_{\mathrm{N}}$ & 12.4 & 12.9 & 16.2 \\
\hline
\end{tabular}

\section{References}

[1] M. Leslie and M. J. Gillan, J. Phys. C 18, 973 (1985).

[2] G. Makov and M. C. Payne, Phys. Rev. B 51, 4014 (1995).

[3] V. R. Saunders, R. Dovesi, C. Roetti, R. Orlando,C. M. Zicovich-Wilson, N. M. Harrison, K. Doll, B. Civalleri, I. J. Bush, Ph. D'Arco, and M. Llunell, CRYSTAL2003 User's Manual (2003).

[4] J. P. Perdew and Y. Wang, Phys. Rev. B 45, 13244 (1992).

[5] R. A. Evarestov, S. Piskunov, E. A. Kotomin, and G. Borstel, Phys. Rev. B 67, 064101(2003).

[6] A. Gulans, R. A. Evarestov, I. Tale, and C. C. Yang, phys. stat. sol. (c) (submitted).

[7] H. J. Monkhorst and J. D. Pack, Phys. Rev. B 13, 5188 (1976). 